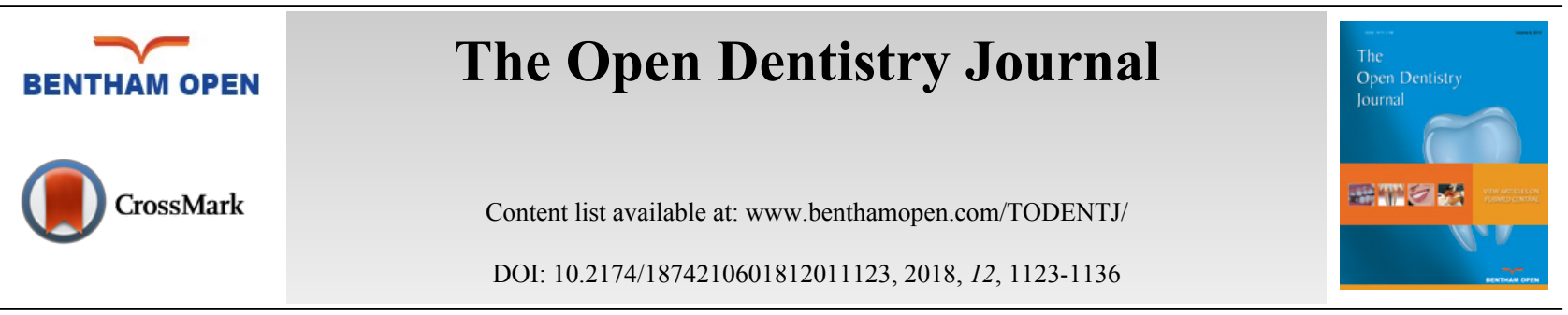

RESEARCH ARTICLE

\title{
The Influence of Impression Material on the Accuracy of the Master Cast in Implant Restorations
}

\author{
Spyridon Stefos ${ }^{1}$, Stefanos Kourtis ${ }^{1, *}$, Aspasia Sarafianou ${ }^{1}$ and Panagiotis Zoidis ${ }^{2}$ \\ ${ }^{I}$ Department of Prosthodontics, Dental School, University of Athens, Thivon Str 2, Athens, Greece \\ ${ }^{2}$ Department of Restorative Sciences, Division of Prosthodontics, College of Dentistry, University of Florida, \\ Gainesville, FL, USA
}

Received: August 10, 2018

Revised: November 14, 2018

Accepted: December 11, 2018

\begin{abstract}
:
Aim:

The precise framework fit is important for the success of implant restorations. The purpose of the present study was to examine the effect of two different impression materials both of their medium viscosity on the master cast accuracy when parallel and inclined implants were used.
\end{abstract}

\section{Materials and Methods:}

An epoxy master cast with three implants was fabricated. The first two implants were parallel to each other and perpendicular to the horizontal plane and the third implant had a 25 inclination in reference to the other two. A passively fitting metal framework that was fabricated over this master cast was used to measure accuracy of fit. Five closed tray impressions for each medium viscosity material (polyether and polyvinyl-siloxane) tested were taken and the respective ten stone casts with three implant analogs were fabricated. The metal framework in the master cast, was fixed in the new specimens and the micro-gap between this prosthesis and the implant analogs was evaluated. The specimens were observed to an optical microscope and digital photography.

\section{Results and Conclusion:}

The data were statistically analysed using a computer software and t-test. Polyether exhibited higher micro-gap mean values ( 93,4 to $61,8 \mu \mathrm{m})$ compared to polyvynil siloxane $(30,47$ to $14,83 \mu \mathrm{m})$. The differences were statistically significant only for implant B. The categorical regression analysis $(p<0.01)$ for all implants showed that the marginal micro-gap was affected by the impression material (94.1\%) and significantly by the type of it. The micro-gap values were higher for polyether compared to polyvinyl-siloxane. The torqued implant did not exhibit any statistically significant effect.

Keywords: Impression materials, Implants, Addition type silicon, Polyether, Polyvinyl-siloxane impressions, Fixed Partial Denture (FPD).

\section{INTRODUCTION}

The use of osseointegrated implants for the restoration of fully or partially edentulous patients has become a widely accepted treatment during the past decades [1 - 11]. From the technical point of view the goal is the fabrication of prosthetic superstructures that fit passively on the implants [7 - 9, 12 - 21] The rigid connection of a Fixed Partial Denture (FPD) to the implants results in a clinical situation where implants, abutments, superstructure and supporting bone act as a single unit $[13,22,23]$.

\footnotetext{
* Address correspondence to this author at the Department of Prosthodontics, Dental School, University of Athens, Thivon Str 2, Athens, Greece; Tel: 306972838900; E-mail: stefkour@dent.uoa.gr
} 
The lack of passive fit combined with the absence of periodontal ligament around the implants, may be the cause of severe problems to the surrounding bone as well as failures to the implants or the prosthetic device [23]. Thus, oral rehabilitation should be initiated with adequate and individualized prosthodontic treatment planning for each clinical situation to provide satisfactory aesthetics and function once the prosthesis is fixed on the implants [23].

Differing from the natural teeth that have a buccal-lingual mobility of 56-108 $\mu \mathrm{m}$, osseointegrated implants are ankylosed to the bone and have no periodontal ligament to compensate for any inaccuracy, showing a minimal mobility $(10 \mu \mathrm{m})$ due to the elasticity of bone tissue $[2,9,11-13,15,22,24,25]$. Consequently, recording the intraoral threedimensional implant position is critical in the realization of implant-supported prostheses to ensure an accurate relationship on the master cast $[4,7,8,12,16,17,20,23,26-29]$.

An inaccurate impression may lead to biological and laboratory problems as a result of the prosthesis' misfit, or even affect the surrounding tissues $[2,7-9,12,17-19,25-27,30]$. Mechanical complications that might arise from non-passive include screw or abutment loosening, screw-, abutment- or implant fracture and occlusal inaccuracy [2, 6, 7, 9, 12, 16 - 19, 26, 28, 30 - 32]. Marginal discrepancy occurring as a result of misfit may also increase plaque accumulation and affect the soft and/or hard tissues around the implant $[6,8,12,16,25,27,28,31]$.

In the daily clinical practice it is difficult or practically impossible to achieve absolute passive fit and the response of bone tissue around implants supporting ill-fitting prostheses remains controversial. Therefore, the impression accuracy of the implants and the proper construction of the master cast remains an important factor for the clinical life of implants.

Most of the existing studies have described various impression techniques, without a solid conclusion as to which technique is preferable. The construction of an implant restoration with an ideal passive fit is difficult because of the numerous clinical and laboratory stages, but also due to the increased number of materials and components that used during fabrication [5, 7 - 10, 26, 28, 31 - 34].

Most authors consider the passive fit of the prostheses as an advantageous factor for the long-term serviceability of the restorations. As a consequence, the importance of an accurate impression, concerning the technique and the impression material is paramount [7, 8, 10, 14, 26, 27, 29, 31, 34 - 36]. The impression materials that are widely used for implant restorations are addition type silicones (polyvinyl siloxane) and polyether. The critical question is whether Polyvinyl Siloxane (VPS) or polyether offer increased accuracy in implant impressions.

\section{AIM}

The purpose of this study was to examine the effect of two different impression materials on the accuracy of the master cast with parallel and inclined implants. The impression materials used were medium viscosity polyvinyl siloxane and polyether with closed tray. The null hypothesis was that there would be no differences in the accuracy of casts produced from impressions made of different impression materials.

\section{MATERIALS AND METHODS}

An epoxy resin master cast was fabricated utilizing three 3,4 $\mathrm{mm}$ diameter external connection dental implants (Xive TG, Friadent/Dentsply Co, Mannheim Germany). The implants were embedded in the epoxy resin with the use of an electronic paralleling device (Fig. 1). Two implants (implants A, B) were placed perpendicularly to the horizontal plane and parallel to each other ( 0 degree inclination), while the third implant (implant $C$ ) was placed with a 25 degree inclination to the vertical plane. Although a CAD/CAM constructed framework would have been more precise, it was decided to construct and measure a waxed metal framework, in order to be more realistic to everyday dental practice.

A screw-retained metal framework was waxed, sprued and cast from a Co-Cr base metal alloy. After casting, the framework was cut, fit and soldered in order to achieve passive fit over the implants (Fig. 2). The fit of the framework was examined under magnification under a microscope with magnification 40x. This framework was used as reference point for comparisons and as control. The framework was initially screwed on the first implant analog (implant A) with a torque of $20 \mathrm{Ncm}$. The resulting initial micro-gap was measured at the implant-analog surface for implants B and C with the use of an optical microscope (Leica Microsystems, Wetzlar Germany) and pictures of the fitting surfaces of all the analogs were taken at a standardized magnification of 40X. The framework was later fixed by the retaining screw on the inclined analog (implant C) and the fit was accordingly evaluated on the other two implants (implants A and B). These initial micro-gap values were recorded for each specimen, in order to be used for the calculation of the final micro-gap value. 


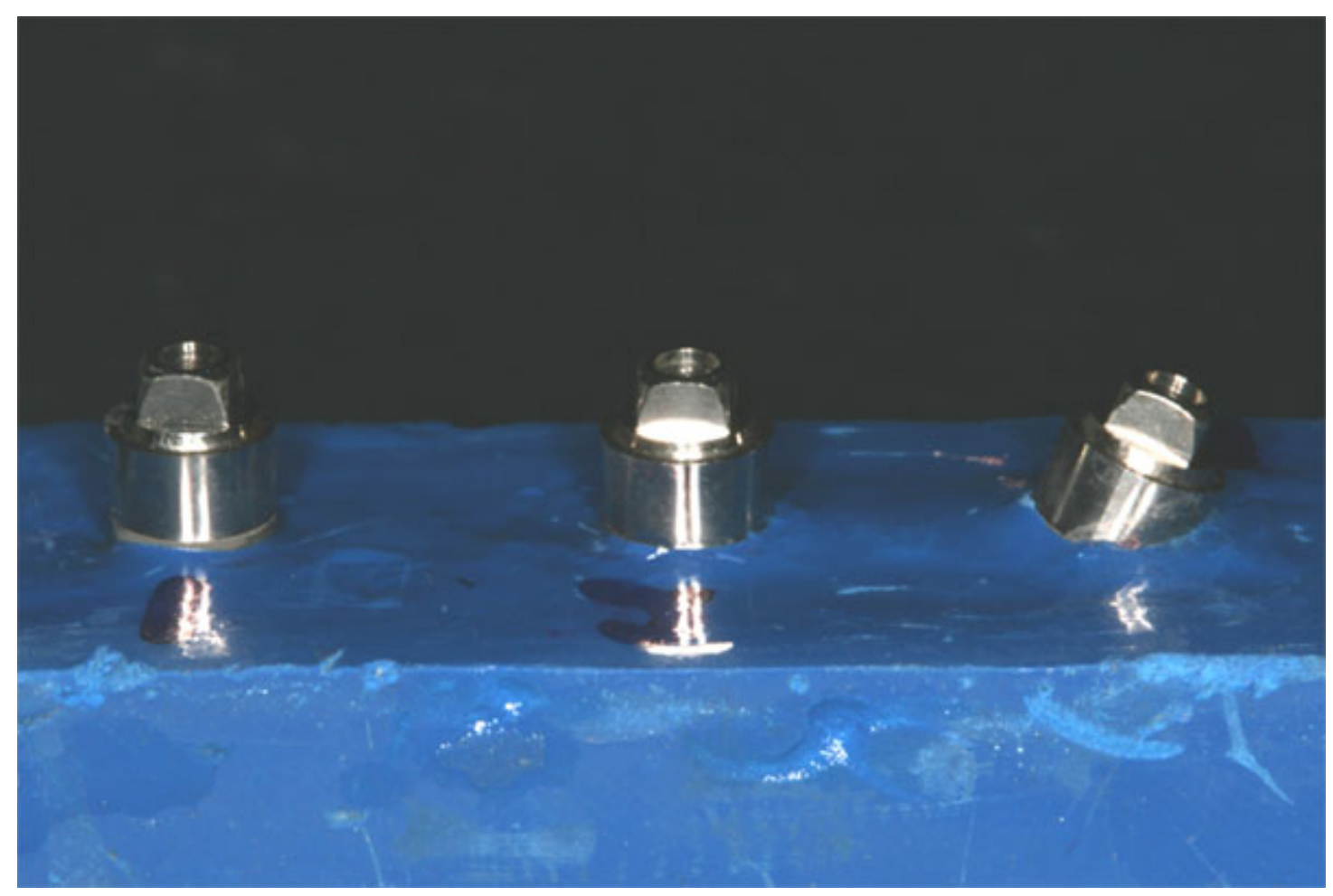

Fig. (1). Epoxy resin master cast made with implants A, B and C (left to right).

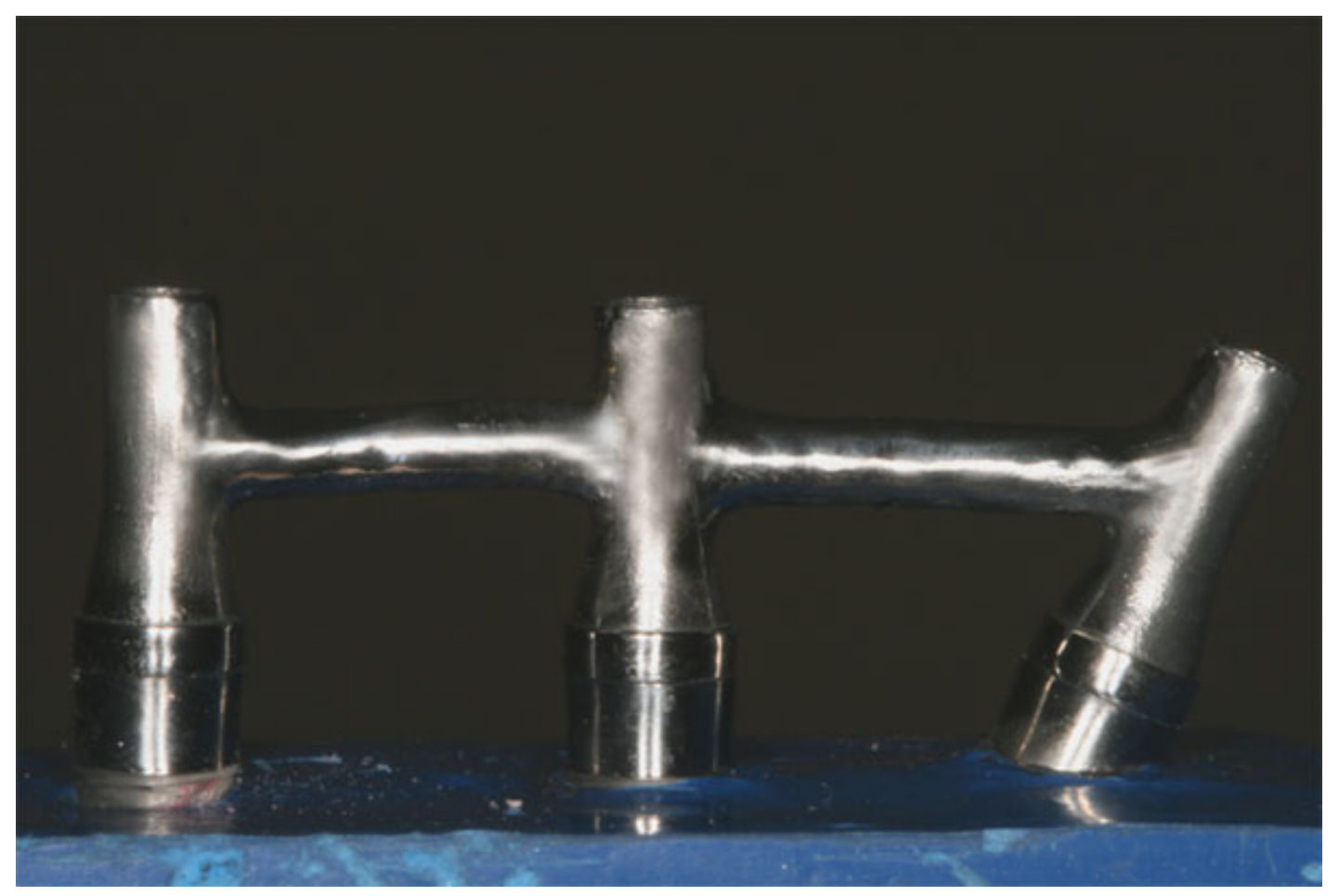

Fig. (2). The metal framework fitted on the mastercast.

Five non-parallel orientation grooves $(2 \mathrm{~mm}$ deep) were created on the sides of the master cast surface using rotary instruments to allow precise orientation of the custom tray. A light-polymerizing resin tray material (Triad, Dentsply Co, Frankfurt Germany) was used for the fabrication of two custom impression trays, one for each impression technique tested. 
Closed-tray transfer copings (Xive TG Impression Posts D 3, 4-4, 5 mm, Friadent/Densply Co, Mannheim Germany) were connected to the implants on the epoxy resin cast. Impression material thickness consistency was ensured by injecting exactly $15 \mathrm{ml}$ of bite registration addition silicone material (Exabite ${ }^{\mathrm{TM}}$ II NDS, GC America Inc.) around the copings and $35 \mathrm{ml}$ of it inside the trays, creating a consistent $2 \mathrm{~mm}$ space.

A photopolymerizing resin tray material (Triad, Dentsply Co, Frankfurt Germany) was used for the fabrication of two custom impression trays, one for each impression material tested. The tray material was positioned over the copings and the silicone and carefully packed onto the master cast up to complete engagement of the orientation grooves. Lightpolymerization was performed in a light curing device (Triad 2000 Visible Light Curing Unit, Dentsply Co, Frankfurt Germany) for 6 minutes. Following polymerization the trays were stored at room temperature $(23 \pm 1 \mathrm{C})$ and humidity $(50 \pm 10 \%)$ for 24 hours according to manufacturer's instructions. The same custom tray was used for all the five impressions of each group in order to avoid discrepancies of thickness of the impression materials. The respective tray adhesive material (Polyether Adhesive, 3M/ESPE AG, Seefeld Germany and Silfix, Dentsply GmBH, Konstanz Germany) was applied on the inner surface of each custom tray and allowed to dry for 30 minutes.

For the purposes of this study, a polyether (Impregum Penta ${ }^{\mathrm{TM}}$ (3M/ESPE Co) and polyvinylsiloxane impression material (Aquasil Ultra Monophase, Densply Co) both of medium viscosity, were used. Closed tray transfer copings (Xive TG Impression copings, Friadent/Densply Co) were connected to the implants with a 20 Ncm torque, according to the manufacturer's instructions. The same custom tray was used for all the five impressions of each material. The respective tray adhesive material (Polyether Adhesive, 3M/ESPE AG and Silfix, Dentsply GmBH) was applied on the inner surface of each custom tray and allowed to dry for 30 minutes.

The polyether impression material was mixed in a special automixing device (Pentamix ${ }^{\mathrm{TM}} 2,3 \mathrm{M} / \mathrm{ESPE}$ AG) and syringed around the copings (total volume: $50 \mathrm{ml}$ ), while the tray was loaded and positioned in order to engage the orientation grooves. The tray was held with finger pressure until completion of polymerization. The polyvinyl siloxane was mixed with a hand held mixing pistol and syringed around the posts (total volume: $50 \mathrm{ml}$ ). The tray was filled with impression material, positioned and held in the same manner.

Ten impressions, five for each tested material, were made (Fig. 3). The impressions were visually inspected for the presence of bubbles or other deficiencies and stored at room temperature (23 $\pm 1 \mathrm{C})$ and humidity $(50 \pm 10 \%)$ for 24 hours. They were washed with tap water for 10 seconds and dried with an air stream.

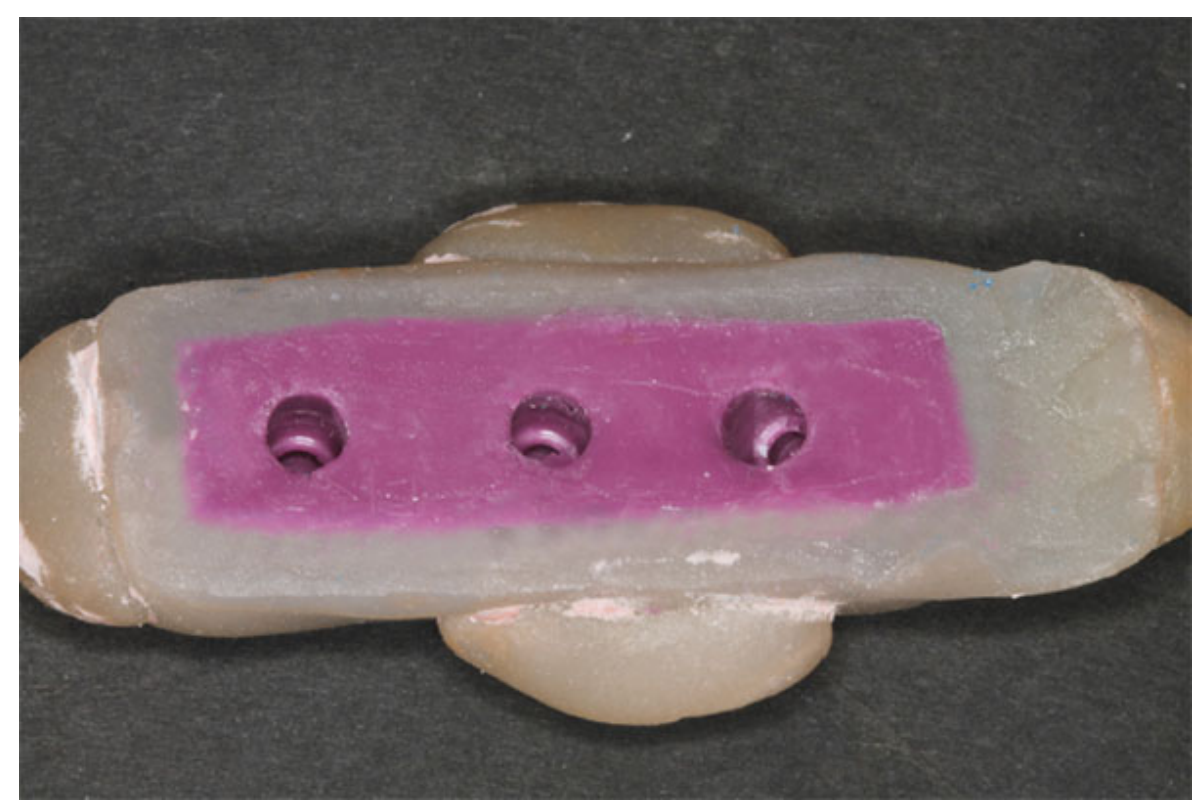

Fig. (3). Impression with the custom tray.

The transfer copings were removed from the epoxy resin cast, connected to external hex implant analogs (Xive TG Implant laboratory analogs, Friadent/Densply Co, Mannheim Germany) and the hand tightened coping-analog assembly was repositioned in the retentive features in the impression material. The copings were checked for stability and 
absence of rotational movement. The new master casts were fabricated using hard dental stone. Type IV die stone material (Silky Stone, WhipMix Co, Louisville, KY, USA) was mixed with water in the ratio suggested by the manufacturer in a vacuum mixing device (Whip Mix Combination Unit, WhipMix Co, Louisville, KY, USA) for 30 seconds. The mixed stone was poured in the impressions and allowed to set for 24 hours. Five specimens (stone casts), each containing three implant analogs, were fabricated for each material tested (1S-5S and 1P-5P) (Fig. 4).

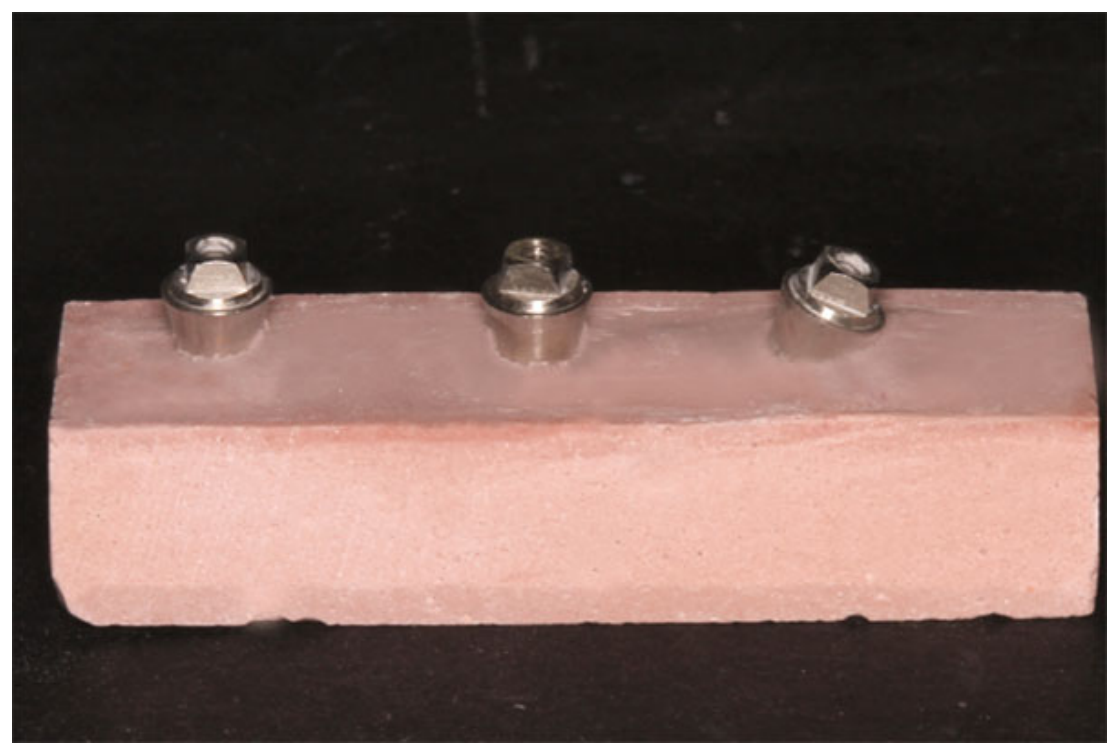

Fig. (4). Die stone specimen.

The resulting micro-gaps were evaluated using the passively fitting cast framework that was fabricated on the initial epoxy resin master cast on each implant for every specimen. The framework was initially screwed on the distal perpendicular analog (Implant A) with a torque of $20 \mathrm{Ncm}$ (Fig. 2). The resulting micro-gap was measured at the implant-analog surface with the use of an optical microscope (Leica Microsystems, Wetzlar Germany) and pictures of the fitting surfaces of all the analogs were taken at a standardized magnification of 40X (Figs. 5-7). Six pictures were taken at the contact surfaces of each implant analog, two at each of the mesial, distal and labial analog surfaces. The pictures were analyzed with the use of a software program (Adobe Photoshop CS4, Adobe Systems, California, USA).

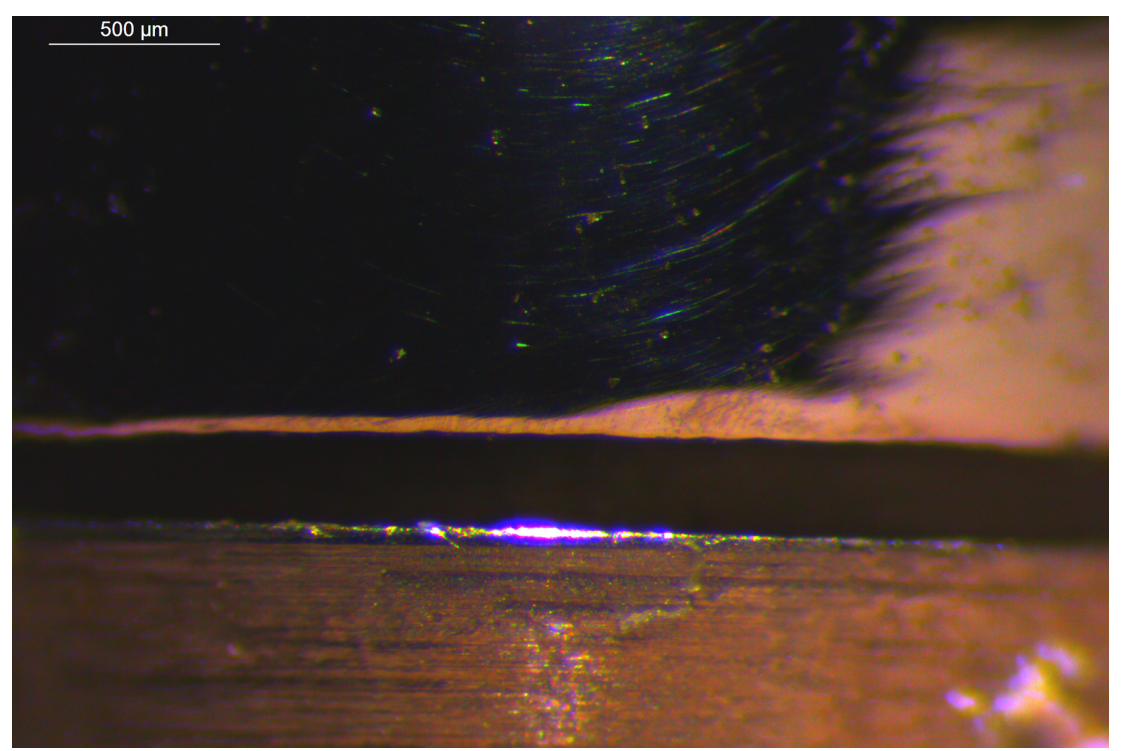

Fig. (5). Photo of the microgap at the "labial" surface (40x). 


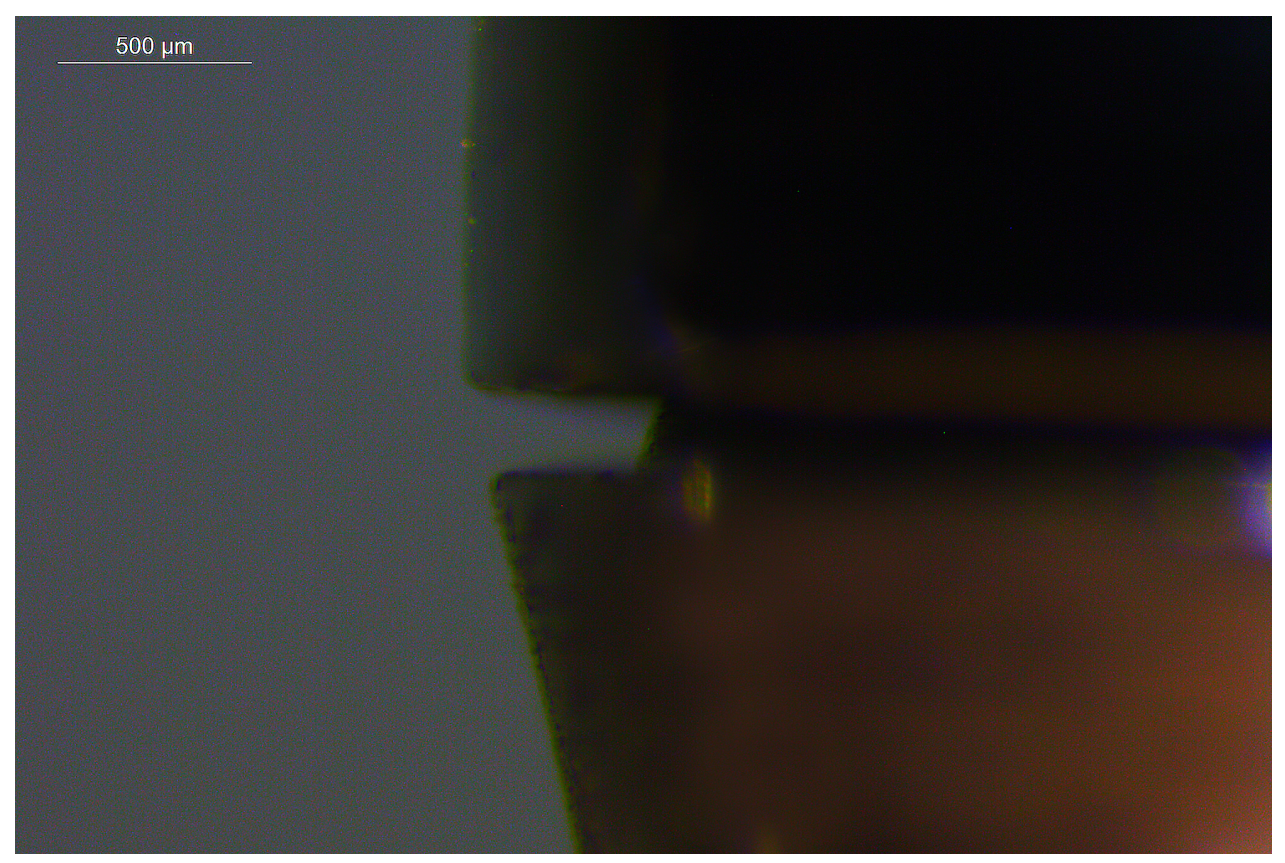

Fig. (6). Photo of the microgap at the "mesial" surface (40x).

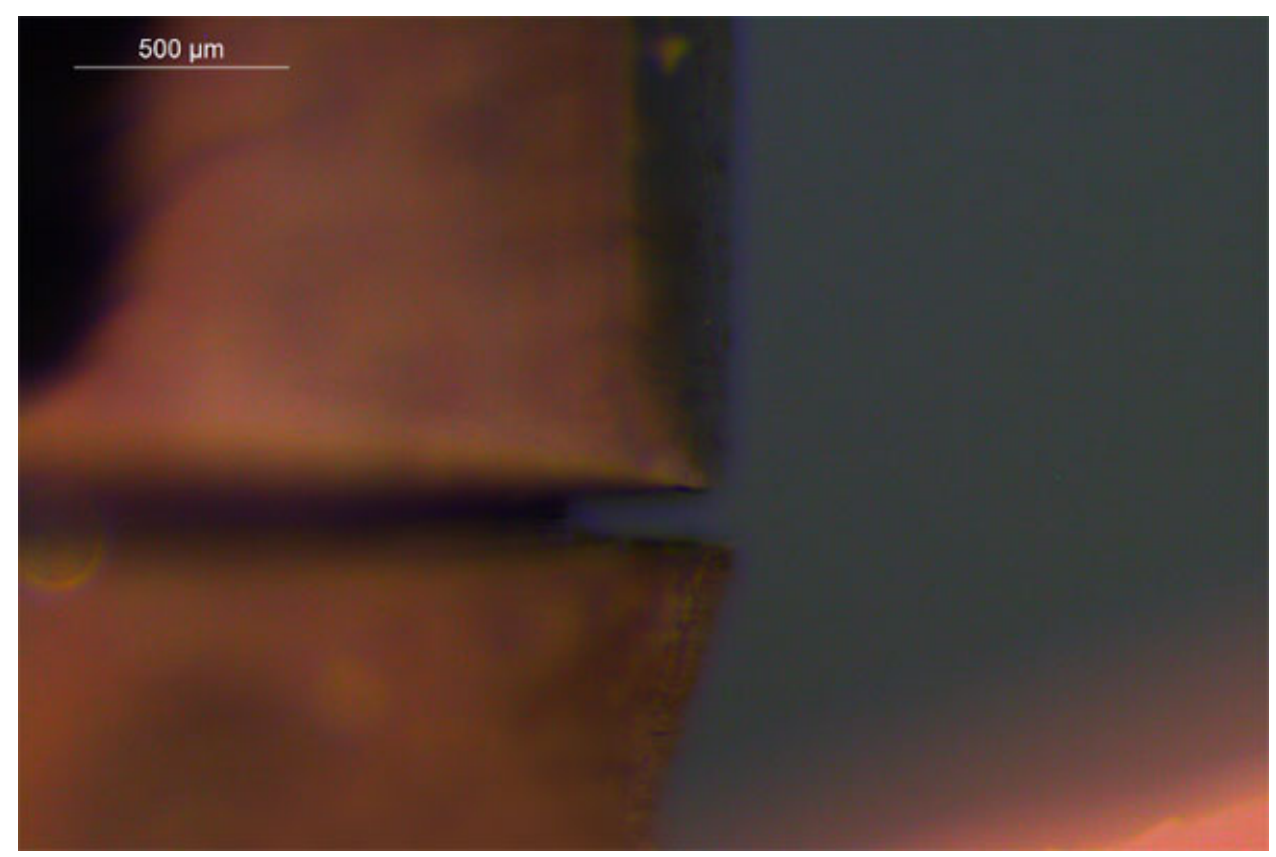

Fig. (7). Photo of the microgap at the "distal" surface (40x).

For each picture two points, one at the outermost point of the metal framework and one at the corresponding edge of the analog were selected and the distance between them was measured by means of the reference bar depicted on the screen as the photo was projected by the software program. Three measurements for each picture were performed and their mean value was calculated in $\mu \mathrm{m}$ (Figs. 5-7). The three surfaces of each analog were evaluated and a general mean value ( $g$ mean) was calculated for the micro-gap on each implant. Since the fixing of the framework by tightening the screw on the most distal perpendicular implant (Implant A) resulted in the elimination of the micro-gap on this particular implant, only the measurements of the non-screwed implants were used (Implants B and C). The framework was afterwards screwed on the inclined analog (Implant C) and the fit was evaluated in the same way on the other two implants (Implants A and B). 
The fit of the preexisting metal framework had already been evaluated accordingly. The framework was fixed by the screw in a similar manner on the epoxy resin cast (reference cast) at $20 \mathrm{Ncm}$ and its fit was also measured. The resulting values of the micro-gap on the epoxy resin cast were considered as a "tare" value and were subtracted from the corresponding values measured on the specimens (casts) made from polyether or silicone impressions.

The data of the micro-gap values were statistically evaluated by ANOVA and Categorical Regression analysis with the use of statistical software programs (SPSS 13.0, Statistica).

\section{RESULTS}

The overall results from the measurements of the gap (gmean) at the implant-framework interface are presented in Diagram 1. Differences were noted concerning the general mean value of the micro-gaps for the three implants and the two impression materials. Polyether exhibited higher micro-gap general mean values when compared to polyvynil siloxane. For each implant the micro-gap values for polyvynil siloxane and polyether were compared using the t-test. The differences were statistically significant only for Implant B. This might be attributed to the fact that there had been no zero measurements for Implant B, since the framework was torqued either on Implant A or C. As a result, micro-gap values for Implant B were present on all measurements. On the contrary, micro-gap measurements of zero value for Implants $\mathrm{A}$ and $\mathrm{C}$ were present when the framework was tightened on the corresponding implant, a fact that affected the resulting micro-gap general mean.

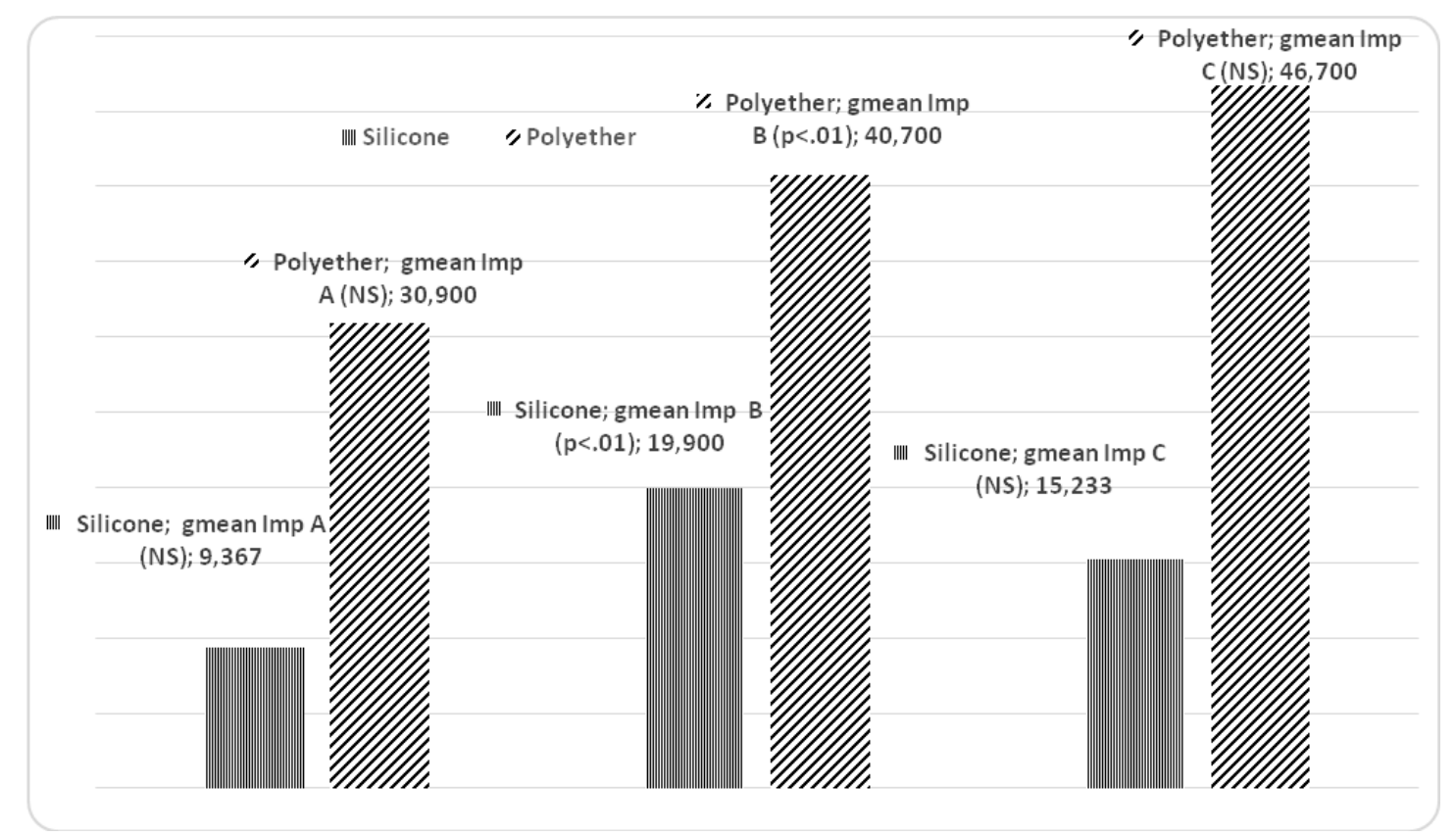

Diagram 1. General mean values of the microgap (g mean) in $\mu \mathrm{m}$ for implants A, B and C. NS: No statistical significance.

In Diagram 2 the tests of between subjects (implants and impression materials) effects on the marginal micro-gap between the implant analog and the metal framework are presented. A statistically significant difference concerning only the factor "impression material" was found $(p<0.01)$. The factor "torqued implant" did not exhibit any statistically significant effect on the impression accuracy.

Diagram 3 depicts the general mean values of the micro-gap at the framework-analog interface for all implants. For silicone impressions the micro-gap between the prosthesis and the analogs was $14,83 \mu \mathrm{m}$ and when polyether was used, the micro-gap between the above surfaces was $39,43 \mu \mathrm{m}$, no matter which implant was torqued. Diagram 1 depicts the mean value of the micro-gap on implant $\mathrm{C}$ when the framework was tightened on implant $\mathrm{A}$. As expected, the microgap in Implant A was zero for both impression materials. The mean values for silicone was $18.73 \mu \mathrm{m}$ and for polyether $61.8 \mu \mathrm{m}(\mathrm{F}=5.079),(p<0.05)$. In Diagram 4 the mean value of the micro-gap on implant $\mathrm{A}$ is presented, when the framework was tightened on implant C. As expected, the micro-gap in Implant $\mathrm{C}$ was zero for both impression materials. The mean values for silicone was $30.47 \mu \mathrm{m}$ and for polyether $93.4 \mu \mathrm{m}(\mathrm{F}=5.30),(p<0.05)$. 


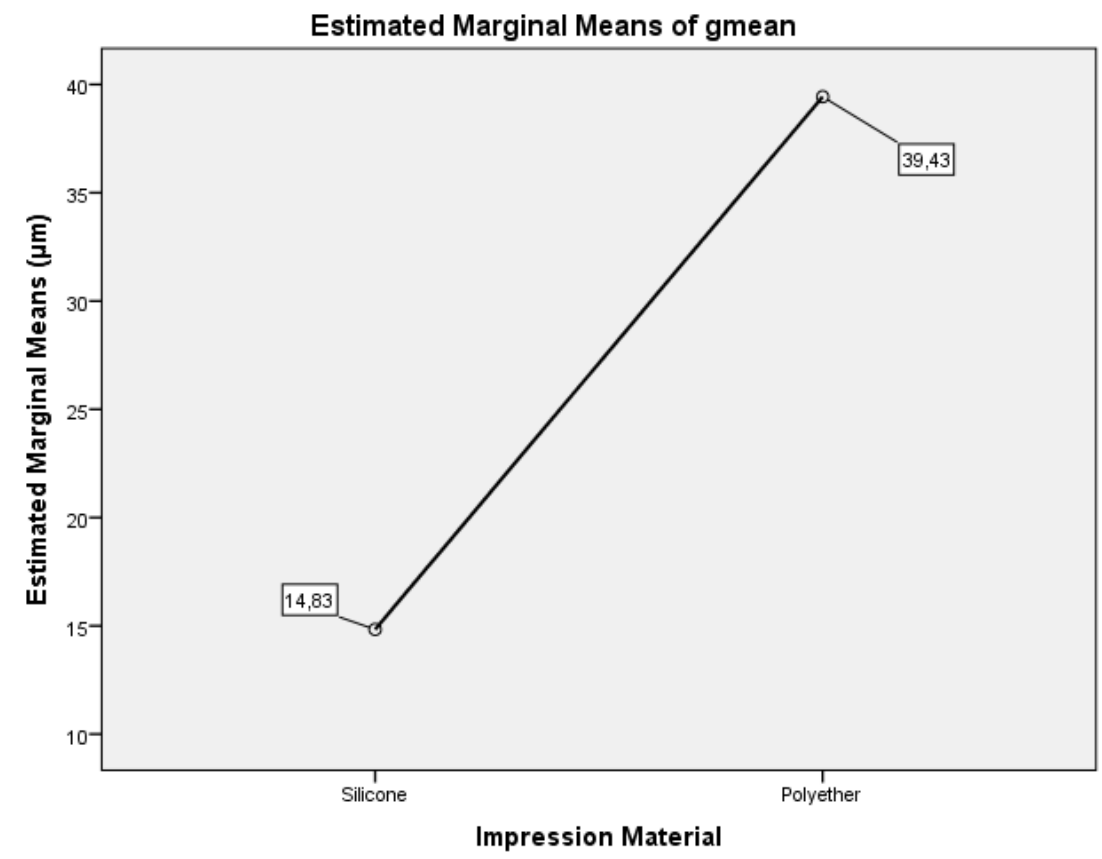

Diagram 2. General mean values (g mean) of the microgap for the different impression materials for all implants.

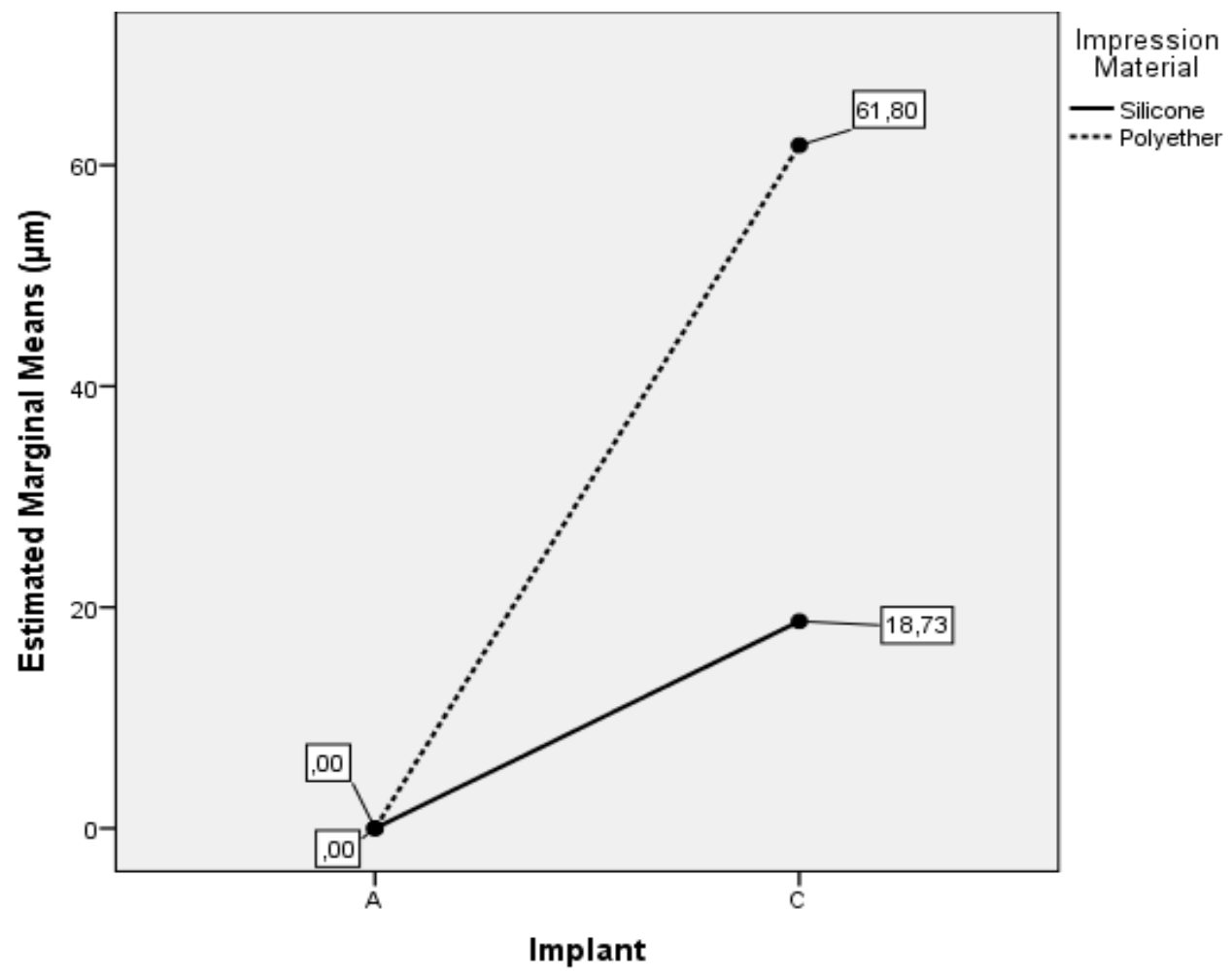

Diagram 3. Mean values of the microgap on Implant C. $(F=5.079),(p<0.05)$. 


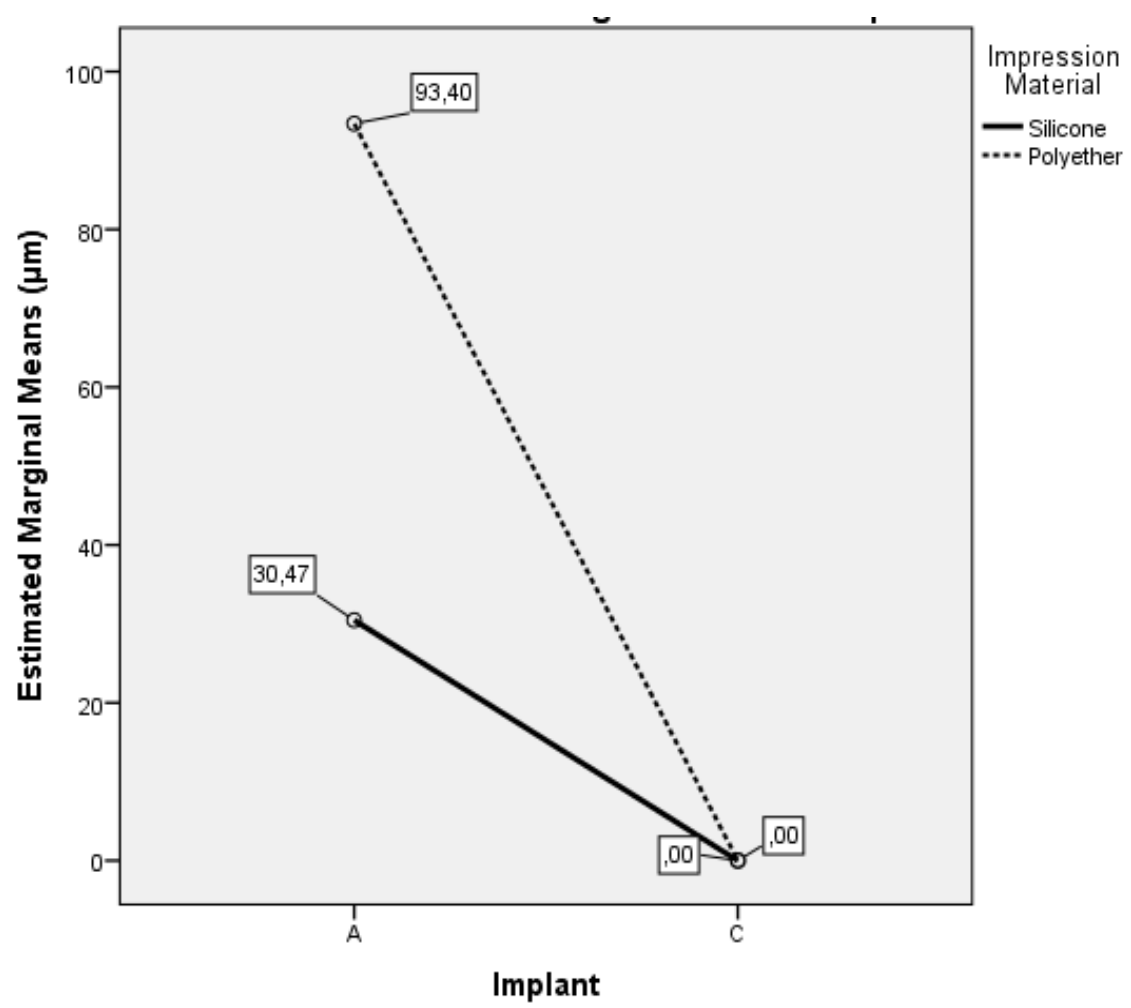

Diagram 4. Mean values of the microgap on Implant A. $(\mathrm{F}=5.30),(\mathrm{p}<0.05)$.

A categorical regression statistical analysis was performed in order to further investigate the effect between the two predicting factors (predictors), the impression material (polyvinyl siloxane or polyether) and the torqued implant (A or C). This analysis indicated the impact of each factor on the examined dependent variable (micro-gap) (Tables 1-4). It may be observed that the impression accuracy was mostly affected by the impression material (94.1\%) and significantly less by the torqued implant $(5.9 \%)$.

Table 1. Analysis tests of between subjects effects for implants (A, C) and impression material.

\begin{tabular}{|c|c|c|c|c|c|}
\hline \multicolumn{6}{|c|}{ Tests of Between-Subjects Effects } \\
\hline Source & Type III Sum of Squares & df & Mean Square & $\mathbf{F}$ & Sig. \\
\hline Corrected Model & $3565,240^{\mathrm{a}}$ & 3 & 1188,413 & 4,439 & 019 \\
\hline Intercept & 14724,356 & 1 & 14724,356 & 55,005 &, 000 \\
\hline impr_mater & 3025,800 & 1 & 3025,800 & 11,303 & ,004 \\
\hline implant & 341,689 & 1 & 341,689 & 1,276 & ,275 \\
\hline impr_mater * implant & 197,751 & 1 & 197,751 & ,739 & ,403 \\
\hline Error & 4283,072 & 16 & 267,692 & - & - \\
\hline Total & 22572,667 & 20 & - & - & - \\
\hline Corrected Total & 7848,311 & 19 & - & - & - \\
\hline
\end{tabular}

a. R Squared =, 454 (Adjusted R Squared $=, 352$ )

Dependent Variable: gmean

Table 2. Categorical regression analysis of the marginal microgap. The predictors were the impression material and the torqued implant. $(F=4.070),\left(R^{2}=0.32\right),(p<0.05)$

\begin{tabular}{|c|c|c|c|c|c|}
\hline \multicolumn{6}{|c|}{ ANOVA } \\
\hline- & Sum of Squares & df & Mean Square & $\mathbf{F}$ & Sig. \\
\hline Regression & 6,476 & 2 & 3,238 & 4,070 & ,036 \\
\hline Residual & 13,524 & 17 & ,796 & - & - \\
\hline Total & 20,000 & 19 & - & - & - \\
\hline
\end{tabular}


Table 3. Statistical significance in the categorical regression.

\begin{tabular}{|c|c|c|c|c|c|}
\hline \multicolumn{3}{|c|}{ Coefficients } & \multirow{2}{*}{ df } & \multirow{2}{*}{ F } & \multirow{2}{*}{ Sig. } \\
\hline & Beta & Standardized Coefficients & 1 & $\mathbf{1 3 , 5 7 8}$ & $\mathbf{, 0 0 2}$ \\
\hline Impression Material &, 552 &, 150 & 1 & 1,085 &, 312 \\
\hline Implant &, 138 &, 132 & 1 & \\
\hline
\end{tabular}

Dependent Variable: gmean

Table 4. Correlations and tolerance between the two factors affecting general marginal accuracy.

\begin{tabular}{|c|c|c|c|c|c|c|}
\hline \multicolumn{8}{|c|}{ Correlations and Tolerance } \\
\hline \multirow{2}{*}{-} & \multicolumn{3}{|c|}{ Correlations } & \multicolumn{3}{|c|}{ Tolerance } \\
\cline { 2 - 7 } & Zero-Order & Partial & Part & & \multicolumn{3}{|c|}{} \\
\cline { 3 - 7 } &, 552 &, 557 &, 552 & $\mathbf{, 9 4 1}$ & 1,000 & 1,000 \\
\hline Impression Material &, 138 &, 166 &, 138 &, 059 & 1,000 & 1,000 \\
\hline
\end{tabular}

Dependent Variable: g mean

\section{DISCUSSION}

The purpose of this study was to examine the effect of two different medium viscosity impression materials on the accuracy of the master cast with parallel and inclined implants using the closed tray impression technique. The null hypothesis was that neither type of impression material (polyether and polyvinyl siloxane) would affect the framework fit. On the basis of the recorded data and the evaluation of the results, the null hypothesis was rejected. Both materials had a significant effect on the accuracy of the experimental casts, both for parallel and inclined implants.

A standard amount of medium viscosity polyether and polyvinyl siloxane impression materials were used with the closed tray technique. The innovations in this study were the use of an optical microscope and a software to measure the micro-gap between a restoration and the implant analogs and the use of medium viscosity impression materials.

Baig et al., [37] in an extended literature review covering a 20 year period, showed that silicones and polyether were the preferred materials for implant impressions. 59 studies were selected in total for evaluation and 15 studies compared polyvinyl siloxane and polyether. Among them 11 studies found no differences between the two materials in terms of impression accuracy, in contrast to our study, where differences existed. 30 studies analyzed the splint effect, 13 found splinting of the impression post resulting in greater accuracy and 13 others elicited no differences between splinting and non-splinting of the posts. In 12 studies the implant inclination was examined as a factor influencing the impression accuracy and found significant differences in accuracy for inclinations reaching 20-25 and this finding is in accordance with the results of the present study. Finally, among the 25 studies examining pick-up (open- tray) and transfer (closed tray) impression techniques, 12 favored open tray over closed- tray impression, especially with increased numbers of implants. In the present study only the closed- tray technique was examined.

Lee et al., [31], in a systematic review investigated the accuracy of impression techniques and materials for implants. Of the 41 articles that were included, 14 compared the accuracy of closed and open tray impression techniques. Of the 14 studies, 5 showed more accurate impressions with the non-splinted open-tray technique, 2 with the closed-tray technique and 7 showed no difference between them.

In the closed-tray technique the impression copings remain fixed on the implants after the removal of the impression. The transfer of the impression copings from the mouth to the implant analogs and their repositioning to the impression material on the tray may induce inaccuracy, because they may not be exactly seated to the original position. This is believed to be the primary source of error of this technique, especially when more than 4 implants were examined [38]. In the present study 3 implants were used in order to minimize the risk of false positioning of the impression copings and the resulting inaccuracy of the master cast.

Eleven of the studies reviewed by Lee et al. [31], compared the accuracy of polyether and polyvinyl-silicone impression materials. In ten of them no difference between the 2 materials was reported and only 1 showed greater accuracy of the impressions with polyvinyl siloxane. This result was probably related to the impression materials and their accuracy, concerning the implant position. Lee et al., [28], in an experimental in-vitro study investigated the effect of impression material on the accuracy of the cast. Open tray impressions were made on a stone master model that was 
fabricated with 5 implant analogs embedded parallel to each other and placed in different depths below the model's surface. Medium-body polyether or a combination of putty and light-body polyvinyl siloxane was used as impression materials. Horizontal and vertical distances were measured with a microscope and it was concluded that polyvinylsiloxane was more accurate [28].

\section{LIMITATIONS}

A possible limitation concerning the design of the present study was the fact that a not so precise waxed metal framework (comparing to a CAD/CAM framework) was used for the measurements, in order to be more realistic concerning what happens to everyday dental practices. Another important limitation was that the evaluated micro-gaps between the prosthesis and the implant analog were not depicted 3-dimensionally (3D), but in 2 dimensions.

Assessment of the distortion occurring in working casts produced by different impression has been investigated using a variety of methods [39] These include stereophotogrammetry, reflex microscopy, laser interferometry, scanning electron microscopy, microtomography, confocal microscopy and mechanical digitisers. For dental applications, surface measurement sensitive to changes at the microns $(\mu \mathrm{m})$ level is necessary and current methods involving the use of three-dimensional co-ordinate measuring machines are designed to meet these specifications $[17,22,26,35,39,40]$.

In the present study the microgap between the metal framework and the implant analogs was evaluated. The specimens were observed in an optical microscope from which photos were taken and analyzed using a computer software. Before that stage, impressions were prepared with medium-viscosity polyether and with Medium-Viscosity Silicone (VPS), contrary to all previous studies that used putty and light-body Polyvinyl-Silicones (VPS). That process imitates the common procedure in the dental practitioner's everyday clinical life.

\section{CONCLUSION}

Within the limitations of this in-vitro study the following can be concluded:

○ Both impression materials significantly affected the accuracy of the casts, both for parallel and for inclined implants.

○ Polyether impressions exhibited significantly higher marginal gap values compared to polyvinyl-siloxane.

- The marginal gap between implants and framework was affected mainly by the impression material and secondarily by the implant inclination or their interaction.

o For inclined implants the casts resulting from polyvinyl-siloxane impressions were more accurate compared to the polyether impressions.

o For both impression materials the micro-gap values of the inclined implants were significantly higher compared to the parallel implants. Implant inclination of 25 degrees may affect the accuracy of the resulting final cast.

\section{ETHICS APPROVAL AND CONSENT TO PARTICIPATE}

Not applicable.

\section{HUMAN AND ANIMAL RIGHTS}

No animals/humans were used for studies that are the basis of this research.

\section{CONSENT FOR PUBLICATION}

Not applicable

\section{CONFLICT OF INTEREST}

The authors declare no conflict of interest, financial or otherwise. 


\section{ACKNOWLEDGEMENTS}

The authors thank Professor George Heliades, Director of the Biomaterials Department at the National and Kapodistrian University of Athens Dental School for his thorough help and support.

\section{REFERENCES}

[1] Brånemark PI, Hansson BO, Adell R, et al. Osseointegrated implants in the treatment of the edentulous jaw. Experience from a 10-year period. Scand J Plast Reconstr Surg Suppl 1977; 16: 1-132.

[PMID: 356184]

[2] Adell R, Lekholm U, Rockler B, Brånemark PI. A 15-year study of osseointegrated implants in the treatment of the edentulous jaw. Int J Oral Surg 1981; 10(6): 387-416. [http://dx.doi.org/10.1016/S0300-9785(81)80077-4] [PMID: 6809663]

[3] Albrektsson T, Zarb G, Worthington P, Eriksson AR. The long-term efficacy of currently used dental implants: A review and proposed criteria of success. Int J Oral Maxillofac Implants 1986; 1(1): 11-25. [PMID: 3527955]

[4] Branemark PI, Albrektsson T, Zarb GA. Tissue-integrated prostheses: Osseointegration in clinical dentistry. Quintessence Publ. Co., Chicago 1985: pp.11-76, 253-257.

[5] Liou AD, Nicholls JI, Yuodelis RA, Brudvik JS. Accuracy of replacing three tapered transfer impression copings in two elastomeric impression materials. Int J Prosthodont 1993; 6(4): 377-83.

[PMID: 8240649]

[6] Phillips KM, Nicholls JI, Ma T, Rubenstein J. The accuracy of three implant impression techniques: A three-dimensionalanalysis. Int J Oral Maxillofac Implants 1994; 9(5): 533-40.

[7] De La Cruz JE, Funkenbusch PD, Ercoli C, Moss ME, Graser GN, Tallents RH. Verification jig for implant-supported prostheses: A comparison of standard impressions with verification jigs made of different materials. J Prosthet Dent 2002; 88(3): 329-36. [http://dx.doi.org/10.1067/mpr.2002.128070] [PMID: 12426505]

[8] Naconecy MM, Teixeira ER, Shinkai RS, Frasca LC, Cervieri A. Evaluation of the accuracy of 3 transfer techniques for implant-supported prostheses with multiple abutments. Int J Oral Maxillofac Implants 2004; 19(2): 192-8.

[PMID: 15101589]

[9] Choi JH, Lim YJ, Yim SH, Kim CW. Evaluation of the accuracy of implant-level impression techniques for internal-connection implant prostheses in parallel and divergent models. Int J Oral Maxillofac Implants 2007; 22(5): 761-8. [PMID: 17974110]

[10] Wenz HJ, Hertrampf K. Accuracy of impressions and casts using different implant impression techniques in a multi-implant system with an internal hex connection. Int J Oral Maxillofac Implants 2008; 23(1): 39-47. [PMID: 18416411]

[11] Mpikos P, Tortopidis D, Kourtis S. Impressions in implant-supported fixed prosthetic restorations(in greek, English abstract). Odontostomatological Progress 2013; 67(2): 226-40.

[12] Sahin S, Cehreli MC. The significance of passive framework fit in implant prosthodontics: current status. Implant Dent 2001; 10(2): 85-92. [http://dx.doi.org/10.1097/00008505-200104000-00003] [PMID: 11450418]

[13] Vigolo P, Fonzi F, Majzoub Z, Cordioli G. An evaluation of impression techniques for multiple internal connection implant prostheses. J Prosthet Dent 2004; 92(5): 470-6. [http://dx.doi.org/10.1016/j.prosdent.2004.08.015] [PMID: 15523336]

[14] Assif D, Nissan J, Varsano I, Singer A. Accuracy of implant impression splinted techniques: Effect of splinting material. Int J Oral Maxillofac Implants 1999; 14(6): 885-8.

[PMID: 10612928]

[15] Burawi G, Houston F, Byrne D, Claffey N. A comparison of the dimensional accuracy of the splinted and unsplinted impression techniques for the Bone-Lock implant system. J Prosthet Dent 1997; 77(1): 68-75. [http://dx.doi.org/10.1016/S0022-3913(97)70209-9] [PMID: 9029468]

[16] Wee AG, Aquilino SA, Schneider RL. Strategies to achieve fit in implant prosthodontics: A review of the literature. Int J Prosthodont 1999; 12(2): 167-78. [PMID: 10371920]

[17] Herbst D, Nel JC, Driessen CH, Becker PJ. Evaluation of impression accuracy for osseointegrated implant supported superstructures. J Prosthet Dent 2000; 83(5): 555-61. [http://dx.doi.org/10.1016/S0022-3913(00)70014-X] [PMID: 10793388]

[18] Watanabe F, Uno I, Hata Y, Neuendorff G, Kirsch A. Analysis of stress distribution in a screw-retained implant prosthesis. Int J Oral Maxillofac Implants 2000; 15(2): 209-18.

[PMID: 10795453] 
[19] Burns J, Palmer R, Howe L, Wilson R. Accuracy of open tray implant impressions: An in vitro comparison of stock versus custom trays. J Prosthet Dent 2003; 89(3): 250-5. [http://dx.doi.org/10.1067/mpr.2003.38] [PMID: 12644799]

[20] Chee W, Jivraj S. Impression techniques for implant dentistry. Br Dent J 2006; 201(7): 429-32. [http://dx.doi.org/10.1038/sj.bdj.4814118] [PMID: 17031344]

[21] Holst S, Blatz MB, Bergler M, Goellner M, Wichmann M. Influence of impression material and time on the 3-dimensional accuracy of implant impressions. Quintessence Int 2007; 38(1): 67-73. [PMID: 17216911]

[22] Vigolo P, Majzoub Z, Cordioli G. Evaluation of the accuracy of three techniques used for multiple implant abutment impressions. J Prosthet Dent 2003; 89(2): 186-92.

[http://dx.doi.org/10.1067/mpr.2003.15] [PMID: 12616240]

[23] Assunção WG, Cardoso A, Gomes EA, Tabata LF, dos Santos PH. Accuracy of impression techniques for implants. Part 1: Influence of transfer copings surface abrasion. J Prosthodont 2008; 17(8): 641-7. [http://dx.doi.org/10.1111/j.1532-849X.2008.00308.x] [PMID: 19090889]

[24] Assif D, Marshak B, Schmidt A. Accuracy of implant impression techniques. Int J Oral Maxillofac Implants 1996; 11(2): $216-22$. [PMID: 8666454]

[25] Sorrentino R, Gherlone EF, Calesini G, Zarone F. Effect of implant angulation, connection length and impression material on the dimensional accuracy of implant impressions: An in vitro comparative study. Clin Implant Dent Relat Res 2010; 12(1): e63-76. [PMID: 19438937]

[26] Jemt T, Rubenstein JE, Carlsson L, Lang BR. Measuring fit at the implant prosthodontic interface. J Prosthet Dent 1996; 75 (3): $314-25$. [http://dx.doi.org/10.1016/S0022-3913(96)90491-6] [PMID: 8648581]

[27] Conrad HJ, Pesun IJ, DeLong R, Hodges JS. Accuracy of two impression techniques with angulated implants. J Prosthet Dent 2007; 97(6): 349-56. [http://dx.doi.org/10.1016/S0022-3913(07)60023-7] [PMID: 17618917]

[28] Lee H, Ercoli C, Funkenbusch PD, Feng C. Effect of subgingival depth of implant placement on the dimensional accuracy of the implant impression: An in vitro study. J Prosthet Dent 2008; 99(2): 107-13. [http://dx.doi.org/10.1016/S0022-3913(08)60026-8] [PMID: 18262011]

[29] Mpikos P, Kafantaris N, Tortopidis D, Galanis C, Kaisarlis G, Koidis P. The effect of impression technique and implant angulation on the impression accuracy of external- and internal-connection implants. Int J Oral Maxillofac Implants 2012; 27(6): 1422-8. [PMID: 23189292]

[30] Ness EM, Nicholls JI, Rubenstein JE, Smith DE. Accuracy of the acrylic resin pattern for the implant-retained prosthesis. Int J Prosthodont 1992; 5(6): 542-9. [PMID: 1307014]

[31] Lee H, So JS, Hochstedler JL, Ercoli C. The accuracy of implant impressions: A systematic review. J Prosthet Dent 2008; $100(4)$ : $285-91$. [http://dx.doi.org/10.1016/S0022-3913(08)60208-5] [PMID: 18922257]

[32] Eckert SE, Choi YG, Sánchez AR, Koka S. Comparison of dental implant systems: Quality of clinical evidence and prediction of 5-year survival. Int J Oral Maxillofac Implants 2005; 20(3): 406-15. [PMID: 15973952]

[33] Esposito M, Grusovin MG, Coulthard P, Thomsen P, Worthington HV. A 5-year follow-up comparative analysis of the efficacy of various osseointegrated dental implant systems: A systematic review of randomized controlled clinical trials. Int J Oral Maxillofac Implants 2005; 20(4): 557-68. [PMID: 16161740]

[34] Del'Acqua MA, Arioli-Filho JN, Compagnoni MA, Mollo FdeA Jr. Accuracy of impression and pouring techniques for an implant-supported prosthesis. Int J Oral Maxillofac Implants 2008; 23(2): 226-36. [PMID: 18548918]

[35] Wee AG. Comparison of impression materials for direct multi-implant impressions. J Prosthet Dent 2000; 83(3): 323-31 [http://dx.doi.org/10.1016/S0022-3913(00)70136-3] [PMID: 10709042]

[36] Akça K, Cehreli MC. Accuracy of 2 impression techniques for ITI implants. Int J Oral Maxillofac Implants 2004; 19(4): 517-23. [PMID: 15346748]

[37] Baig MR. Multi-unit implant impression accuracy: A review of the literature. Quintessence Int 2014; 45(1): 39-51. [PMID: 24392494]

[38] Daoudi MF, Setchell DJ, Searson LJ. A laboratory investigation of the accuracy of the repositioning impression coping technique at the implant level for single-tooth implants. Eur J Prosthodont Restor Dent 2003; 11(1): 23-8. [PMID: 12705035]

[39] Forrester-Baker L, Seymour KG, Samarawickrama D, Zou L, Cherukara G, Patel M. A comparison of dimensional accuracy between three different addition cured silicone impression materials. Eur J Prosthodont Restor Dent 2005; 13(2): 69-74. [PMID: 16011234] 
[40] Assuncao WG, Filho HG, Zaniquelli O. Evaluation of transfer impressions for osseointegrated implants at various angulations. Implant Dent 2004; 13(4): 358-66.

[http://dx.doi.org/10.1097/01.id.0000144509.58901.f7] [PMID: 15591998]

\section{(C) 2018 Stefos et al.}

This is an open access article distributed under the terms of the Creative Commons Attribution 4.0 International Public License (CC-BY 4.0), a copy of which is available at: https://creativecommons.org/licenses/by/4.0/legalcode. This license permits unrestricted use, distribution, and reproduction in any medium, provided the original author and source are credited. 